\title{
Reduction of Column Yielding During Earthquakes for Reinforced Concrete Frames
}

\author{
by Gregory L. Kuntz and JoAnn Browning
}

\begin{abstract}
An investigation to reduce the number of columns that are vulnerable to yielding in reinforced concrete frames subjected to earthquakes is described. Simple limit analysis is used to demonstrate that a reasonable minimum column-girder strength ratio cannot be defined to eliminate yielding in columns of regular frames. A method is developed for reducing the number of columns vulnerable to yielding by applying a strength reduction factor to the girders in the upper floor levels of the frames. Nonlinear static and dynamic analyses of 16 reinforced concrete frames demonstrate that drift can be redistributed over the height of the structure and yielding in columns can be reduced by using the suggested girder strength reduction factor. Application is limited by the initial stiffness of the elements because of the increased drift demands in the top portion of the frame and by the allowable reduction in girder strength that will satisfy gravity-load demands.
\end{abstract}

Keywords: analysis; concrete; frame; yield strength.

\section{RESEARCH SIGNIFICANCE}

This study demonstrates that it is not possible to specify a single column-girder strength ratio to eliminate column yielding in regular frames during earthquakes. Furthermore, a minimum strength ratio of 1.2 will likely result in column yielding between $1 / 2$ and $2 / 3$ of the building height, resulting in larger story-drift ratios in the lower portion of the frame where axial loads are largest. At reasonable maximum drifts, this does not threaten life-safety but influences the total damage expected for the frame. An alternative is presented that redistributes drift over the height of the structure by modifying the strengths of upper-story girders.

\section{INTRODUCTION}

As reinforced concrete frames respond to strong ground motion, it is likely that elements of the frame will have nonlinear behavior. The elements that yield may experience large deformations that contribute to increased localized story deformations in the frame. This is especially true when columns undergo inelastic deformations, as the drift at the story with yielding columns may magnify in part caused by the secondary effects of the axial loads. In addition, it is important to minimize the occurrence of yielding in concrete columns, especially near the base of the frame, because of difficulties encountered for detailing these elements for ductile response under high axial loads.

Representative building codes favor a strong-column/ weak-beam philosophy to encourage yielding in the beams rather than the columns of a frame. ACI International (ACI Committee 318 2002) requires that the sum of the nominal moment capacities of the columns at a joint equal or exceed $6 / 5$ times the sum of the moment capacities of the girders framing into that joint. If yielding in the columns can be eliminated, then the building will tend to respond with a stiff spine and drift will be evenly distributed over the height of the structure. This leads to smaller story drifts (the relative drift between two consecutive floor levels) and less subsequent damage in the lower portion of the frame where columns are subjected to high axial loads.

With current standards, it is generally expected that some yielding will occur in columns of the upper stories of buildings, as demonstrated in numerous shaking table tests of reinforced concrete frames and corroborated using nonlinear analysis (that is, Otani and Sozen [1972]; Moehle and Sozen [1978, 1980]; Eberhard and Sozen [1989]; Browning et al. [2000]). The presence of column yielding as determined in these experimental and analytical studies has not presented a threat to the life-safety performance level for the structures. The question remains, however, as to whether eliminating column yielding in frames is possible, and how this might affect the response of regular concrete frames during earthquakes. The damage expected for reinforced concrete frames can be reduced if yielding in the columns and story drift ratios (ratio of story drift to story height) in the lower portion of the building are reduced. This paper presents the results of a study to reduce yielding in columns of reinforced concrete frames.

\section{Objective}

The objective of this paper is to demonstrate the effectiveness of a general required column-girder strength ratio as is currently used in ACI 318-02 (ACI Committee 318 2002) for reducing the likelihood of yielding in columns. An initial analysis is conducted using simple limit analysis of regular reinforced concrete frames to determine the minimum strength ratio required to eliminate column yielding. Possible locations of column yielding also are identified for a minimum strength ratio of 1:2. Localized strength modifications to girders and columns are then investigated to reduce yielding of columns in the middle portion of the frame. An expression is suggested for reducing the girder strengths in the upper portion of regular concrete frames based on the results of a parametric study of 235 frames. The expression is evaluated using static and dynamic nonlinear analysis with a suite of eight earthquake records and 16 regular concrete frames. The effectiveness of using the suggested expression to improve frame performance during response to strong ground motion is presented in terms of the modified yield mechanism identified for the frames, and

ACI Structural Journal, V. 100, No. 5, September-October 2003

MS No. 02-181 received May 13, 2002, and reviewed under Institute publication policies. Copyright (c) 2003, American Concrete Institute. All rights reserved, including the making of copies unless permission is obtained from the copyright proprietors. Pertinent discussion including author's closure, if any, will be published in the JulyAugust 2004 ACI Structural Journal if the discussion is received by March 1, 2004. 
Gregory L. Kuntz is employed by HDR Engineering in St. Louis, Mo, He received his BSCE from the University of Missouri-Rolla in 1997 and his MSCE from the University of Kansas in 2001 .

ACI member JoAnn Browning is an assistant professor at the University of Kansas. Lawrence, Kans. She is a member of ACl Committees 318-D, Flexure and Axial Loads; 341, Earthquake-Resistant Concrete Bridges; 374. Performance-Based Seismic Design of Concrete Buildings; and 408. Bond and Development of Reinforce. ment. Her research interests include dynamic response of concrete buildings, drift capacity of concrete columns, and durability of concrete structures.

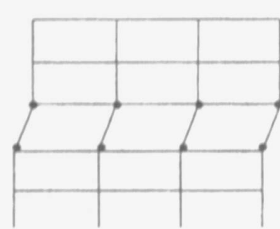

a) Story mechanism

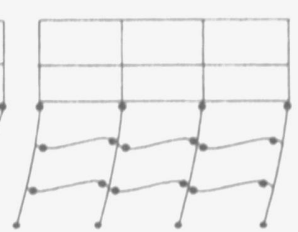

b) Intermediate mechanism

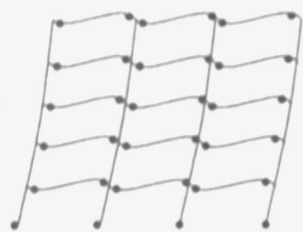

c) Structural mechanism
Fig. 1-Possible sway mechanisms for regular frames.

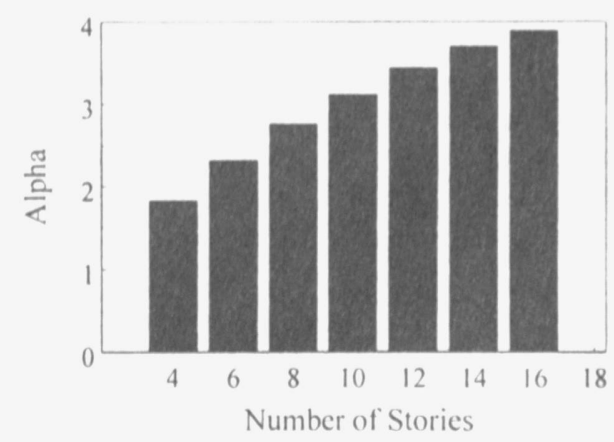

Fig. 2-Minimum $\alpha$ required for structural mechanism.

the modified distribution of drift and story drift ratios over the heights of the frames.

\section{Investigation of column yielding in regular reinforced concrete frames}

The premise of reducing inelastic demands in columns using a strength-based relationship is developed by first exploring the conditions that may lead to the formation of plastic hinges in columns. A simple and convenient method for estimating yield locations in a frame subjected to lateral loads is to determine the controlling sway mechanism using limit analysis. The procedure requires several simplifying assumptions including the selection of a particular distribution of lateral loads, concentration of all element deformations at yield locations, and the limitation of the flexural capacities of all elements to the prescribed yield capacity. Even considering these assumptions, limit analysis provides a reasonable estimate of yield locations at minimal analytical cost.

Consider a set of reinforced concrete frames having four $6.1 \mathrm{~m}$ (20 ft.) bays and ranging from four to 16 stories in twostory increments. For the purpose of this demonstration, the girders for all frames were assumed to have a total depth of $61 \mathrm{~cm}(24 \mathrm{in}$.) and the columns were square with $61 \mathrm{~cm}$ ( 24 in.) dimensions. A strength relationship was defined between columns and girders in a frame by the ratio $\alpha$ where

$$
\alpha=\frac{M_{c t e}}{M_{g}}=\frac{\text { moment capacity of top story, exterior column }}{\text { average moment capacity of girders }}
$$

The girder capacities were assumed to be uniform throughout the frame. The flexural capacities of the girders and columns were adjusted by varying the amount of steel in the members. The longitudinal steel in the column remained constant with story height; therefore, the only variation in column flexural strength was an increase from the top story to the base due to the increasing axial load. An assumed uniform load of $7.66 \mathrm{kPa}\left(160 \mathrm{lb} / \mathrm{ft}^{2}\right)$ considered effective on the frame during an earthquake was used to determine the axial load for each column. Element yield capacities were calculated using the nominal moment capacity from moment-curvature analysis. The concrete compressive strength was $27.6 \mathrm{MPa}$ ( $4000 \mathrm{psi}$ ) and the compressive stress-strain relationship was defined using the model provided by Hognestad (1951). The steel was assumed to behave elastic-plastic with a yield stress of $414 \mathrm{MPa}$ (60 ksi). The girder and column dimensions were selected so that the value of $\alpha$ could be varied while maintaining levels of reinforcement within the allowable ranges provided in ACI 318-02 (ACI Committee 318 2002).

For each frame considered, the value of $\alpha$ was varied and the controlling yield mechanism for the frame was determined using a load distribution that increased linearly with increasing building height. An increase in $\alpha$ was accomplished by increasing the reinforcement in the columns. The load distribution used for the limit analysis affects the calculation of the controlling mechanism for the frame, and may be uniform, linearly increasing with height, in the shape of the fundamental mode of vibration for the structure, or a combination of mode shapes. The locations of column hinges may vary by one or two stories according to the selected distribution of loads. For regular frames of low- to moderateheight, a linear or first-mode approximation is usually adequate to estimate the behavior of the frame under earthquake excitation. A linear load distribution was used in the analyses unless otherwise noted.

All probable yield mechanisms were considered in the analysis, with the typical controlling mechanisms shown in Fig. 1. A structural mechanism (Fig. 1(c)) is the preferred mechanism for a frame because yielding in the columns is limited to the base and distortions are distributed relatively evenly over the entire height of the frame. For each frame, a value of $\alpha$ required to ensure that the structural mechanism was the controlling mechanism was determined and plotted in Fig. 2. Two items of interest are noted from the figure: 1) The minimum criterion of $\alpha=1.2$ is not sufficient to ensure that the structural mechanism will control with any frame; and 2) The value of $\alpha$ required to form the structural mechanism increases with increasing number of stories. This value ranged from 1.8 for a four-story frame to nearly four for the 16-story frame.

The analysis was repeated using linear and uniform lateral load patterns to determine the controlling mechanism for each frame using a minimum value of $\alpha=1.2 \mathrm{Eq}$. (1), which is similar to the requirements defined in $\mathrm{ACI}$ 318-02 ( $\mathrm{ACl}$ Committee 318 2002)

$$
\Sigma M_{c j} \geq \frac{6}{5} \Sigma M_{g j}
$$

where $\Sigma M_{c j}$ is the sum of the flexural strengths of all columns framing into a joint, and $\Sigma M_{g j}$ is the sum of the flexural strengths of all girders framing into that joint. The controlling mechanism was determined for each frame and the location of column yielding above the base is shown in Fig. 3. Column yielding occurred at approximately $1 / 2$ to $2 / 3$ the building height for a uniform load and linear load distribution, respectively. 
From this simple initial study, it is evident that there is a strong likelihood that plastic hinges will form in the columns of regular reinforced concrete frames. In addition, there is not a simple strength-based relationship similar to Eq. (2) that ensures a structural mechanism would control the response of all of the frames considered.

Instead of globally increasing $\alpha$ over the entire frame (which will affect the strengths of all columns in a frame), alternative strategies were investigated for ensuring that the structural mechanism controls. The controlling mechanism is determined by the limiting value of base shear required to form a sway mechanism in the frame. This shear is primarily based on the strengths of the members and the locations of the plastic hinges in the mechanism. Although the rigid lengths of the elements are included in the calculation, they have only a minor effect in the calculated limiting base shear. For this reason, only strength-based solutions were investigated for altering the controlling mechanism for the frame. Although the stiffness of the frame is critical for controlling the total drift expected for the frame, the locations of initial yielding in the frame are primarily affected by the distribution of strength. It should be noted that the degree of inelasticity experienced in the columns of the frame can be reduced by proportioning the frame elements of the structure to limit the total expected drift.

Two options were investigated for improving the controlling mechanism of the frames: 1) increasing column strengths at specific story levels; and 2) decreasing girder strengths at specific story levels. The frames previously described with $\alpha=1.2$ were analyzed using limit analysis to investigate the effectiveness of the two options. For the first option, the locations and levels of strength increase in the columns required to form a structural mechanism were highly variable. As the column strengths are increased, the total shear required to form intermediate mechanisms also is increased, and the total shear required to form the structural mechanism is largely unaffected. For the structural mechanism to control, all of the intermediate mechanisms must have associated total shear forces greater than the total shear force required to form the structural mechanism. This was accomplished by increasing the column strengths at locations in the frames from $10 \%$ of the total height to the top level (Fig. 4). The required factors for the column strengths varied from $3 / 2$ at the stories near the bottom and top to almost 4 at stories near $2 / 3$ the building height.

The second option, decreasing girder strengths at specific floor levels, is more convenient. By decreasing the girder strengths in the upper floor levels of a frame by a selected factor, the total shear force required to form the structural mechanism decreases, whereas the total shear forces required to form the intermediate mechanisms remain unchanged. With a proper combination of number of floor levels and reduction constant $1 / R_{g}$ for girder strength, the structural mechanism becomes the controlling mechanism for the frame as shown in Fig. 5. The numbers of floor levels at the top of the structure with reduced girder strengths are indicated in Fig. 5 next to the data points. Generally, the number of floor levels with reduced girder strength represented the top $40 \%$ of the frame, and the average required reduction constant was approximately 2.2 . This option can only be applied to the extent that strength requirements for gravity load demands allow a reduction in girder strength. If no reduction is possible, then the columns of the frame may be reproportioned to increase the overall strength ratio as well as decrease

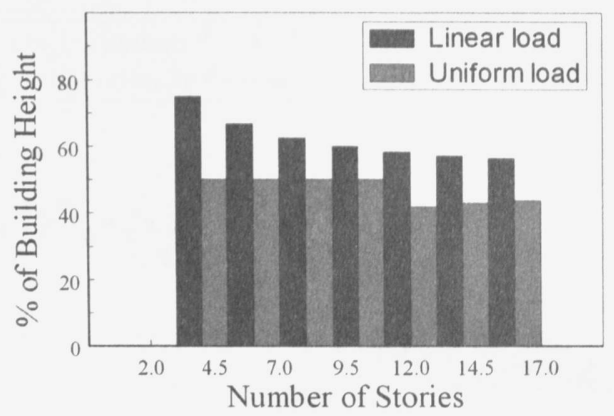

Fig. 3-Location of column yielding for minimum $\alpha=1.2$.

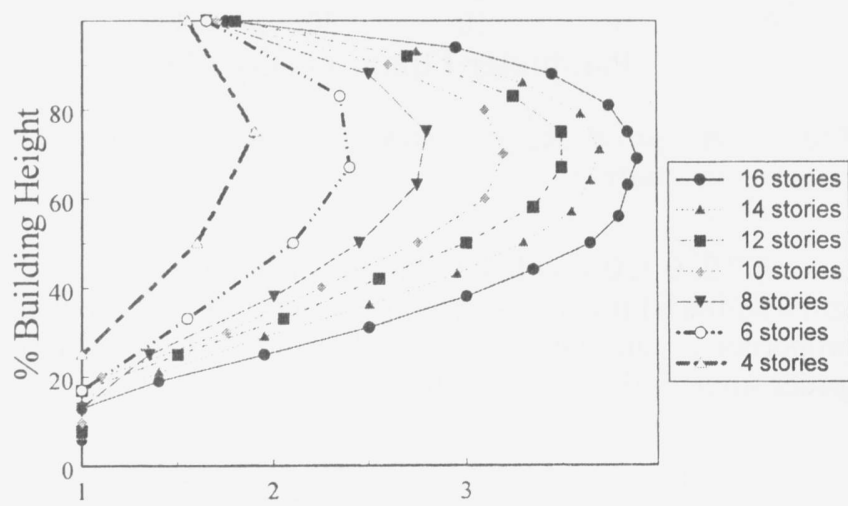

Factor for Column Strength

Fig. 4-Column factors over frame height required for structural mechanism.

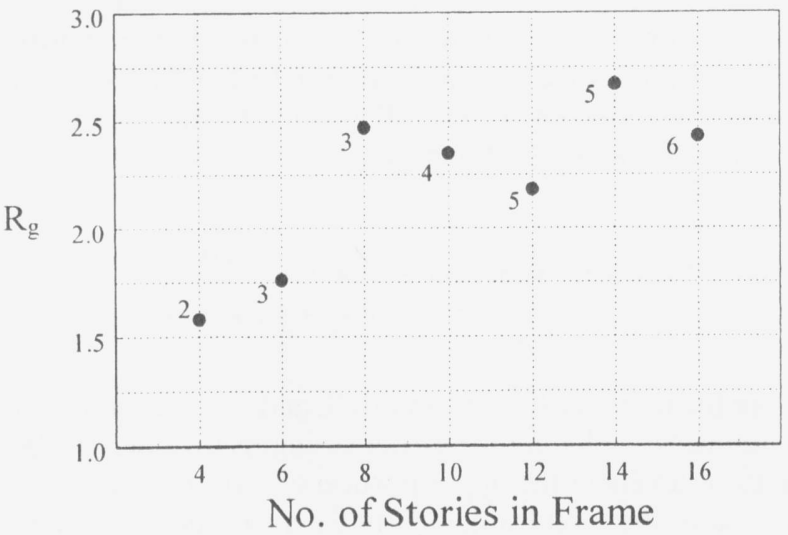

Fig. 5-Reduction of girder strength $\left(1 / \mathrm{R}_{\mathrm{g}}\right.$ factor) required for structural mechanism.

the total deformation demands expected for the structure. The second option, decreasing girder strengths at specific floor levels, was selected for further investigation because it is simpler to apply and it modifies the strengths of fewer elements in the frame.

\section{Parametric analysis}

A parametric analysis was performed using limit analysis to determine the required strength-reduction factor for the upperstory girders of regular frames that will ensure the structural mechanism is the controlling mechanism. The parameters used in the analysis included: number of stories $N_{s}=4,8,12,16$; number of bays $N_{b}=4,6$; square column dimension $h_{c}$ where

$$
h_{c}=\sqrt{\frac{P_{\max }}{c \cdot f_{c}^{\prime}}}
$$




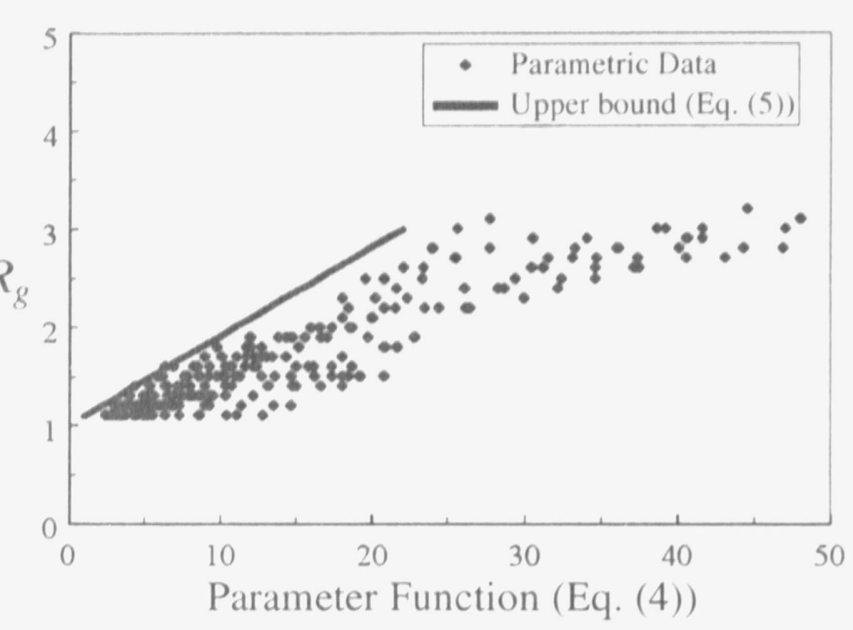

Fig. 6-Required $\mathrm{R}_{\mathrm{g}}$ for structural mechanism from parametric study.

and $c=0.2,0.3,0.4$; column reinforcement ratio $\rho=1,2,3$, and $4 \%$; initial $\alpha=1$ to 4 (as applicable for given element proportions); and the fraction of floor levels with reduced girder strength $\beta=0$ to 0.5 where

$$
\beta=\frac{\text { number of floor levels with reduced } M_{g}}{N_{s}}
$$

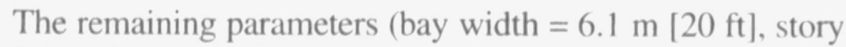
height $=3.0 \mathrm{~m}[10 \mathrm{ft}], f_{c}^{\prime}=27.6 \mathrm{MPa}[4000 \mathrm{psi}]$, and a linear load distribution) were not varied. Using these parameters, a combination of variables was determined that would provide a relationship for the required girder reduction factor. Figure 6 shows the required $R_{g}$ for all frames plotted against the determined parameter function

$$
\text { Parameter function }=\frac{N_{s} \cdot N_{b} \cdot \sqrt{\rho \cdot h_{c}}}{\left(N_{b}+1\right)+\beta \cdot \alpha^{2}}
$$

where the units for $h$ is $\mathrm{cm}$ and $\rho, \beta$, and $\alpha$ are dimensionless fractions. By reducing the girder strengths by a factor $1 / R_{g}$ at the floor levels in the upper portion of a frame (defined as a fraction of the total frame height $\beta$ ), a structural mechanism controlled and yielding of the columns was limited to the base. There is a linear increasing trend in the data beginning with a value of $R_{g}$ equal to 1 and increasing to a value of approximately 3 . The upper-bound line representing this trend may be expressed

$$
\begin{aligned}
& R_{g}=1+\frac{N_{s} \cdot N_{b} \cdot \sqrt{\rho \cdot h_{c}}}{11 \cdot\left(N_{b}+1\right) \cdot \beta \cdot \alpha^{2}}, h_{c} \mathrm{~cm} \\
& {\left[R_{g}=1+\frac{N_{s} \cdot N_{b} \cdot \sqrt{\rho \cdot h_{c}}}{7 \cdot\left(N_{b}+1\right) \cdot \beta \cdot \alpha^{2}}, h_{c}, \text { in }\right]}
\end{aligned}
$$

with all parameters previously defined. A reasonable maximum value of $R_{g}$ to be used is 3 . It is important to emphasize that the expression represents an upper-bound solution, so that if a lower value of $R_{g}$ is used because of gravity load demands, it remains likely that the inelastic response of the columns will be reduced or eliminated.

\section{Nonlinear analysis of frames with reduced girder} strengths in upper floors

The preceding analysis and development of Eq. (5) is based on limit analysis of simple frames. To examine the effects of using the equation to modify the strength of girders in a wider variety of frame structures, nonlinear static and dynamic analyses of 16 notional frames was completed. The frames were modified using Eq. (5) to reduce girder strengths in the upper floor levels. The nonlinear analyses were conducted to determine whether yielding in the columns could be reduced, and, if possible, the effects of this reduction on the behavior of the frames subjected to earthquake motion. The parameters used to proportion the frames included $N$, $=4,8,12,16$; span length $=6.1$ and $9.1 \mathrm{~m}(20$ and $30 \mathrm{ft}$. $)$; and square column dimension $h_{c}$ with $c=0.2,0.35$. In addition. all frames had four bays, $3.0 \mathrm{~m}$ ( $10 \mathrm{ft}$.) story heights, and $\rho=0.02$. The compressive strength of the concrete was assumed to be $27.6 \mathrm{MPa}(4000 \mathrm{psi})$ and the yield stress in the steel was assumed to be $414 \mathrm{MPa}(60 \mathrm{ksi})$.

The proportioning technique used to dimension the columns (Eq. (3)) was selected to represent a range of frames in regions of high seismicity. The axial load ratios defined using $c$ represent conditions close to the balance load condition $(c=$ $0.35)$ and nearly half that load condition $(c=0.2)$. It has been shown that columns proportioned to have axial load ratios below the balance condition tend to have higher drift limits than those proportioned at or above the balance load condition (Matamoros and Sozen 2003; Park, Priestley, and Gill 1982). Although lateral loads are not explicitly considered in the design of the frames, the resulting column dimensions and reinforcement ratios are reasonable for frames in regions of high seismic demand. Girder dimensions were also selected to represent typical frame dimensions in regions of high seismicity. Other simplifications, including uniform longitudinal steel in the elements, were necessary to facilitate the study of a large number of hypothetical frames.

It is recognized that the true strength contribution from the frame components will influence the distribution of yielding in the frame. The strength of a component is affected by many factors, including the actual material properties. contribution of slab reinforcement, variable reinforcement ratios, and the effective girder flange. Selection of element dimensions will affect not only the strengths but also the rotational demands on the elements. For the purposes of this study, the calculated column and girder strengths were assumed to represent the existing strengths of elements for the given range of frame structures. Strength gain in the elements past the yield condition is facilitated using a constant post-yield slope in the moment-curvature relationship described in the following section. Other variations in element strength due to the factors listed previously are topics for other investigations.

\section{Unmodified frames}

To proportion the frames, column dimensions of the fourand eight-story frames were assumed to be constant over the height and were selected using Eq. (3). The column dimensions were reduced at midheight of the 12- and 16-story frames using Eq. (3). Total girder depths were set equal to $1 / 10$ the span length. The girders were $\mathrm{T}$-shaped elements. When selecting the dimensions of the girders, the effective flange width could be defined as narrow as the width of the girder or as wide as the distance between girders. Flange widths for the proportioned girders were selected considering the impact on the overall 
Table 1-Girder strength reduction factor $\boldsymbol{R}_{\boldsymbol{g}}$ used for analyzed frames

\begin{tabular}{|c|c|c|c|c|c|c|c|c|c|c|}
\hline No. stories & $\begin{array}{l}\text { Bay width, } \\
\mathrm{m}(\mathrm{ft})\end{array}$ & $\begin{array}{c}\text { Frame period, } \\
\mathrm{s}\end{array}$ & $\begin{array}{l}\text { No. of stories } \\
\text { used in Eq. (5) }\end{array}$ & \begin{tabular}{|c|}
$c$ \\
Eq. (3) \\
\end{tabular} & $\begin{array}{l}M_{g}, \mathrm{kN}-\mathrm{m} \\
(\mathrm{k}-\mathrm{ft})\end{array}$ & $\alpha$ & $\begin{array}{l}\text { No. of floor levels } \\
\text { with reduced } M_{g}\end{array}$ & $\beta$ & $R_{g}$ & $\begin{array}{c}M_{g, r e d}, \mathrm{kN}-\mathrm{m} \\
(\mathrm{k}-\mathrm{ft})\end{array}$ \\
\hline \multirow{4}{*}{4} & $6.1(20)$ & 0.66 & 4 & 0.35 & $296(218)$ & 0.54 & 2 & 0.500 & $1.7^{*}$ & $172(127)$ \\
\hline & $9.1(30)$ & 0.38 & 4 & 0.35 & $1082(798)$ & 0.61 & 2 & 0.500 & $1.9^{*}$ & $584(431)$ \\
\hline & $6.1(20)$ & 0.48 & 4 & 0.20 & $296(218)$ & 1.15 & 2 & 0.500 & 1.4 & 207 (153) \\
\hline & $9.1(30)$ & 0.29 & 4 & 0.20 & $1082(798)$ & 1.25 & 2 & 0.500 & 1.4 & $751(554)$ \\
\hline \multirow{4}{*}{8} & $6.1(20)$ & 0.87 & 8 & 0.35 & $296(218)$ & 1.57 & 3 & 0.375 & 1.6 & $182(134)$ \\
\hline & $9.1(30)$ & 0.55 & 8 & 0.35 & $1082(798)$ & 1.54 & 3 & 0.375 & 1.8 & $599(442)$ \\
\hline & $6.1(20)$ & 0.71 & 8 & 0.20 & $296(218)$ & 3.47 & 3 & 0.375 & 1.2 & $258(190)$ \\
\hline & $9.1(30)$ & 0.47 & 8 & 0.20 & $1082(798)$ & 3.11 & 3 & 0.375 & 1.2 & $887(654)$ \\
\hline \multirow{4}{*}{12} & $6.1(20)$ & 1.21 & 6 & 0.35 & $296(218)$ & 1.15 & 4 & 0.333 & $1.7^{*}$ & $172(127)$ \\
\hline & $9.1(30)$ & 0.91 & 6 & 0.35 & $1082(798)$ & 1.00 & 4 & 0.333 & $1.9^{*}$ & $584(431)$ \\
\hline & $6.1(20)$ & 1.01 & 6 & 0.20 & $296(218)$ & 2.11 & 4 & 0.333 & 1.3 & $224(165)$ \\
\hline & $9.1(30)$ & 0.78 & 6 & 0.20 & $1082(798)$ & 2.22 & 4 & 0.333 & 1.3 & $805(594)$ \\
\hline \multirow{4}{*}{16} & $6.1(20)$ & 1.48 & 8 & 0.35 & $296(218)$ & 1.57 & 6 & 0.375 & 1.6 & $182(134)$ \\
\hline & $9.1(30)$ & 1.13 & 8 & 0.35 & $1082(798)$ & 1.54 & 6 & 0.375 & 1.8 & $599(442)$ \\
\hline & $6.1(20)$ & 1.27 & 8 & 0.20 & $296(218)$ & 3.47 & 6 & 0.375 & 1.2 & $258(190)$ \\
\hline & $9.1(30)$ & 1.00 & 8 & 0.20 & $1082(798)$ & 3.11 & 6 & 0.375 & 1.2 & $887(654)$ \\
\hline
\end{tabular}

"Girder strength reduction limited by requirements for gravity loads.

frame stiffness so as to allow reasonable drift response to strong ground motion. The effective flanges were defined using a 45-degree projection from the girder base to the base of a $15 \mathrm{~cm}(6 \mathrm{in}$.) slab. The width of the base of the girder was assumed to be equal to $1 / 2$ the total depth. The resulting frames represent a range of typical existing frames with calculated periods shown in Table 1.

An average amount of steel was selected for the girders and columns, using column reinforcement ratios of $2 \%$, negative reinforcement ratios in the girders of $1 \%$, and positive reinforcement ratios in the girders of $0.75 \%$. The contribution of slab steel within the selected effective flange width was not considered for strength calculations. The strength of the girders and columns were checked to be adequate for factored gravity loads (Kuntz and Browning 2001).

Nonlinear analysis was completed using the program LARZ (Saiidi and Sozen 1979a,b; Lopez 1988), which has provided reasonable results for modeling the behavior of reinforced concrete frames in experimental studies (Eberhard and Sozen 1989; Lopez 1988; Lepage 1997) and existing buildings (Browning et al. 2000; Betancourt and Browning 2002). The elements were modeled using a trilinear relationship between moment and curvature, with the corner points defined by cracking, yielding, and ultimate moment conditions. Concrete properties were defined using the relationship described by Hognestad (1951) with a limiting compressive strain of 0.004 , and the steel was assumed to have elastic-plastic behavior. Yield moments were defined as the nominal moment capacity for the member, as determined using moment-curvature analysis. The ultimate moment for each member was defined to provide a constant postyield slope equal to $1 \%$ of the secant slope to yield.

The hysteretic behavior of the elements was defined using the model provided by Takeda, Sozen, and Nielsen (1970) with an unloading slope coefficient of 0.4 . Viscous damping in the system was defined using a coefficient of damping equal to 0.02 . Second-order effects $(P-\Delta)$ also were considered in the analyses.

\section{Modified frames}

Equation (5) was used to modify the girder strengths so that yielding would be unlikely to occur in the columns during response to strong ground motion. A value of $\beta$, which defines the fraction of floor levels at the top of the building with reduced girder strengths, must be selected to calculate a reasonable girder-reduction factor. Because Eq. (5) was developed considering frames with columns having uniform dimensions over the height, $R_{g}$ calculated for the 12- and 16story frames was derived using an effective number of floor levels equal to the number of floor levels from the top of the building to the point where the stiffness has changed. The girder strengths were reduced by dividing the unmodified strength by $R_{g}$. In all cases, the maximum $R_{g}$ was limited by the girder strength required to resist factored gravity loads. Yet, because the expression for $R_{g}$ represents an upper-bound solution, it was anticipated that the nonlinear response of the frames would still improve using the limited reduction factors. The values of $R_{g}$ used for the frames and key strength properties are shown in Table 1.

\section{RESULTS}

The notional frames were analyzed with nonlinear static analysis to determine the effects of using the reduction factor on frame strength and distribution of yielding. A linear load distribution was used in the analysis. Table 2 indicates the location of column yielding calculated in the unmodified and modified frames. In all cases, column yielding was eliminated above the base of the frame when the upper-story girder strengths were modified using $1 / R_{g}$. Figure 7 shows the base shear-roof drift relationship for four of the frames. The base shear strengths of the frames were reduced slightly but represent adequate strength values for reinforced concrete frames. The general shapes of the force-displacement curves are similar for the unmodified and modified frames.

Nonlinear dynamic analysis was completed for all of the frames using a suite of eight unscaled ground motions to determine how yielding in the frames was altered during an earthquake event. The selected earthquakes are described 

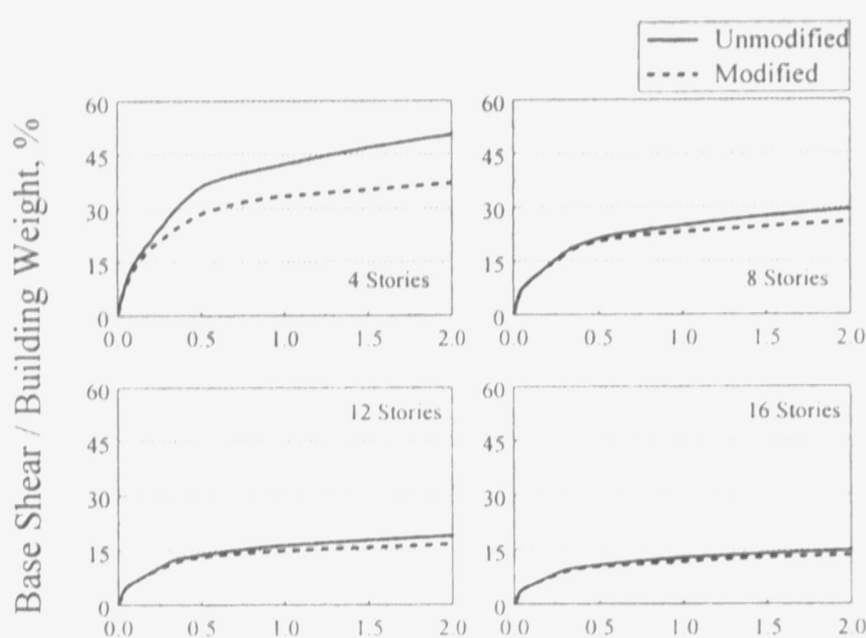

Roof Drift / Building Height, \%

Fig. 7-Static nonlinear analysis of frames with $30 \mathrm{ft}$ bays and $\mathrm{c}=0.35$

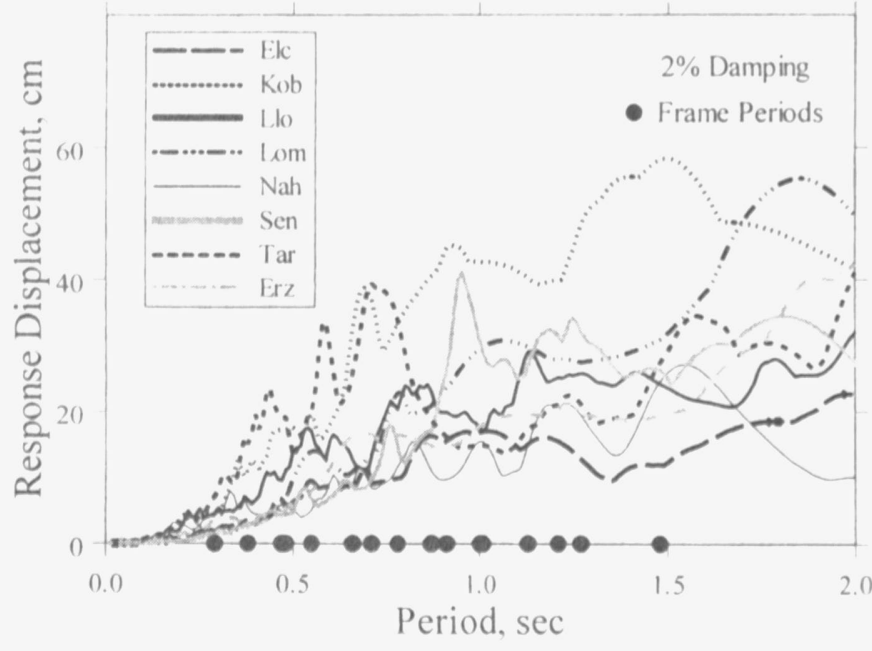

Fig. 8-Displacement response spectra for selected earthquakes.

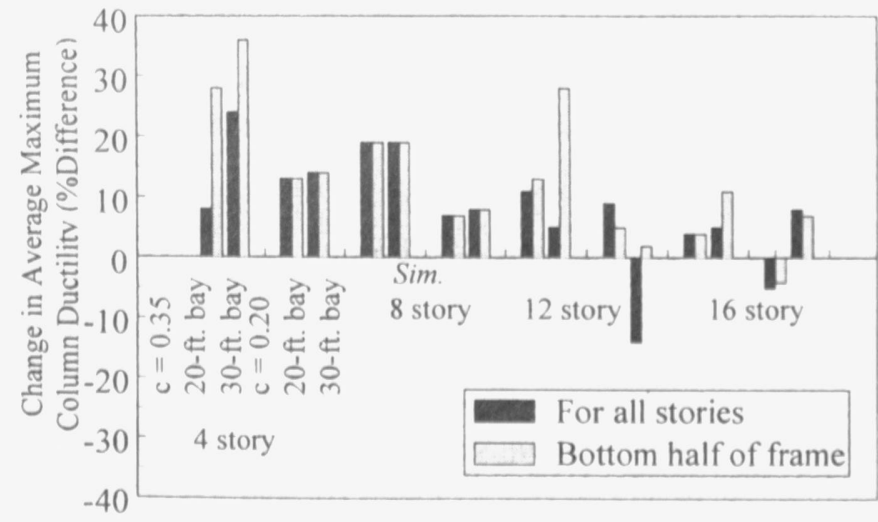

Fig. 9-Change in average maximum column ductility (averaged for all earthquakes).

in Table 3 and represent a variety of site conditions, magnitudes, and frequency content (Kuntz and Browning 2001). Displacement response spectra calculated for the selected records are shown in Fig. 8.

In general, the degree of inelastic response in columns above the base for the modified frames was reduced in the dynamic analyses by using the girder strength reduction
Table 2-Controlling mechanism for static analysis

\begin{tabular}{|c|c|c|c|c|c|}
\hline $\begin{array}{l}\text { No. } \\
\text { stories }\end{array}$ & $\begin{array}{c}\text { Bay width, } \\
\text { m (ft) }\end{array}$ & $\begin{array}{c}c, \\
\text { (Eq. (3)) }\end{array}$ & $\begin{array}{l}\text { Controlling } \\
\text { mechanism } \\
\text { unmodified } \\
\text { frames (all } \\
\text { intermediate) }\end{array}$ & \begin{tabular}{|c|} 
Location of \\
column yielding \\
unmodified \\
frames, \% \\
building height
\end{tabular} & $\begin{array}{c}\text { Controlling } \\
\text { mechanism } \\
\text { modified } \\
\text { frames }\end{array}$ \\
\hline \multirow{4}{*}{4} & $6.1(20)$ & 0.35 & 2nd story & 50.00 & Structural \\
\hline & $9.1(30)$ & 0.35 & 3rd story & 75.00 & Structural \\
\hline & $6.1(20)$ & 0.20 & 3rd story & 75.00 & Structural \\
\hline & $9.1(30)$ & 0.20 & 3rd story & 75.00 & Structural \\
\hline \multirow{4}{*}{8} & $6.1(20)$ & 0.35 & 5th story & 62.50 & Structural \\
\hline & $9.1(30)$ & 0.35 & 6th story & 75.00 & Structural \\
\hline & $6.1(20)$ & 0.20 & 7th story & 87.50 & Structural \\
\hline & $9.1(30)$ & 0.20 & 7th story & 87.50 & Structural \\
\hline \multirow{4}{*}{12} & $6.1(20)$ & 0.35 & 8th story & 66.67 & Structural \\
\hline & $9.1(30)$ & 0.35 & 8th story & 66.67 & Structural \\
\hline & $6.1(20)$ & 0.20 & 9th story & 75.00 & Structural \\
\hline & $9.1(30)$ & 0.20 & 10th story & 83.33 & Structural \\
\hline \multirow{4}{*}{16} & $6.1(20)$ & 0.35 & 11 th story & 68.75 & Structural \\
\hline & $9.1(30)$ & 0.35 & 11 th story & 68.75 & Structural \\
\hline & $6.1(20)$ & 0.20 & 12 th story & 75.00 & Structural \\
\hline & $9.1(30)$ & 0.20 & 13th story & 81.25 & Structural \\
\hline
\end{tabular}

Table 3-Earthquakes used for dynamic analysis of frames

\begin{tabular}{c|c|c|c|c}
\hline Station & Date & Earthquake & PGA. g & Component \\
\hline El Centro (Elc) & $5 / 18 / 1940$ & $\begin{array}{c}\text { Imperial Valley. } \\
\text { Calif. }\end{array}$ & 0.35 & NS \\
\hline Kobe (Kob) & $1 / 17 / 1995$ & $\begin{array}{c}\text { Hyogo-Ken- } \\
\text { Nanbu, Japan }\end{array}$ & 0.83 & NS \\
\hline Llolleo (Llo) & $3 / 3 / 1985$ & Llolleo, Chile & 0.71 & N10E \\
\hline $\begin{array}{c}\text { Loma Prieta } \\
\text { (Hollister) (Lom) }\end{array}$ & $10 / 18 / 1989$ & Loma Prieta, Calif. & 0.37 & NS \\
\hline $\begin{array}{c}\text { Nahinni } \\
\text { Iverson) (Nah) }\end{array}$ & $12 / 23 / 1985$ & Nahinni, Canada & 0.98 & NS \\
\hline $\begin{array}{c}\text { Sendai (Sen) } \\
\text { Tarzana (Tar) }\end{array}$ & $6 / 12 / 1978$ & $\begin{array}{c}\text { Miyagi-Ken-Oki. } \\
\text { Japan }\end{array}$ & 0.26 & NS \\
\hline Erzincan (Erz) & $3 / 13 / 19 / 1994$ & Northridge. Calif. & 0.99 & NS \\
\hline Erzincan. Turkey & 0.48 & EW
\end{tabular}

factor. Yield mechanisms did not form for any of the frames that were modified using $R_{g}$. The changes in average maximum column rotational ductilities (average maximum rotational ductility calculated using the eight earthquake records) are shown in Fig. 9. The rotational ductility is defined as the maximum calculated rotation divided by the rotation associated with yielding of the column. A positive change in the figure indicates a decrease in calculated ductility. The overall change in maximum column ductility ranged from an increase of nearly $15 \%$ for one 12 -story frame to a decrease of over $20 \%$ for a four-story frame. For the bottom halves of the frames, the change in column ductility ranged from an increase of approximately $5 \%$ for a 16 -story frame to a $35 \%$ decrease for a four-story frame.

Nonlinear behavior occurred in all of the girders of the modified frames in lieu of occurring in approximately $2 / 3$ of the girders and the columns of a single floor for the unmodified frames. As a result, the deformations are distributed over the entire building height as compared with approximately $2 / 3$ the building height for the unmodified frames. Figure 10 shows the displacement profile at the maximum roof drift for four of the frames when subjected to the earthquakes that 
caused the maximum, median, and minimum drift response. The figure shows the unmodified and modified building responses. The displaced profiles of the modified frames generally appear to have less drift in the bottom portion of the frame and increased drift near the top as compared with the unmodified frames. The modification is more pronounced for the frames subjected to larger maximum roof drifts. Figure 11 shows the maximum story drift ratios for four of the unmodified and modified frames with average values for all earthquakes indicated by vertical bars. The distribution of drift tends to change from a maximum average value occurring near the base to a more even distribution of story drift. Even with this shift, the maximum story drift ratios do not exceed $2 \%$ in a majority of the cases. For the cases with large story drift ratios, general stiffening of the building using larger column and girder sections is recommended to limit the total amount of drift experienced by the frame as described below.

The general stiffness of the frame is a factor that contributes to the effectiveness of using $R_{g}$ to improve the nonlinear response of the frames. The drift profiles of the frames with larger column sections $(c=0.20)$ were generally less affected by the modification of upper-story girder strengths than the drift profiles of frames with smaller column sections $(c=0.35)$ and having the same girder sections (Kuntz and Browning 2001). This is likely due to the larger initial values of $\alpha$, indicating that the columns are already much stronger than the girders, associated with the unmodified frames. Yet, the frames with more slender columns tend to have higher maximum roof drifts due to a combination of the adjusted drift profile in the upper portion of the frame (as shown in Fig. 9) and the increased flexibility of the frame. With regard to girder stiffness, frames proportioned to have girder strengths that are similar to gravity load demands cannot benefit from using reduced girder strength in the upper floor levels. These limitations are minimized by slightly increasing the proportions of the columns and girders in the frame. By increasing the dimensions of all elements, two things are accomplished: 1) the general stiffness of the frame is increased to limit the total drift as well as element rotational demands; and 2) the girder strengths are increased to allow for a reduction in reinforcement in the upper portions of the frame as determined using Eq. (5).

\section{SUMMARY AND CONCLUSIONS}

The results of this study indicate that yielding in the columns of regular reinforced concrete frames cannot be eliminated with a single reasonable minimum strength ratio between columns and girders framing into a joint. Using simple limit analysis to determine the controlling mechanisms for a number of frames, the minimum required strength ratio to encourage a
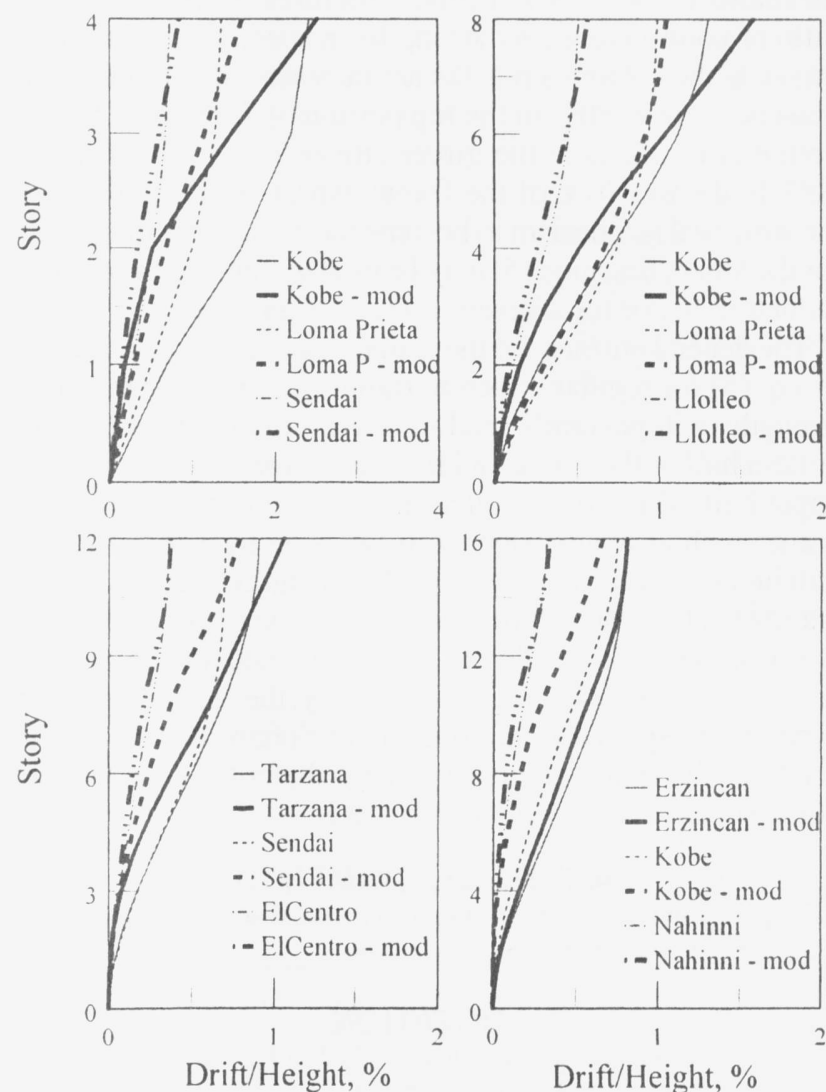

Fig. 10-Displacement profile from dynamic analysis at maximum roof drift for $30 \mathrm{ft}$. bays and $\mathrm{c}=0.35$.
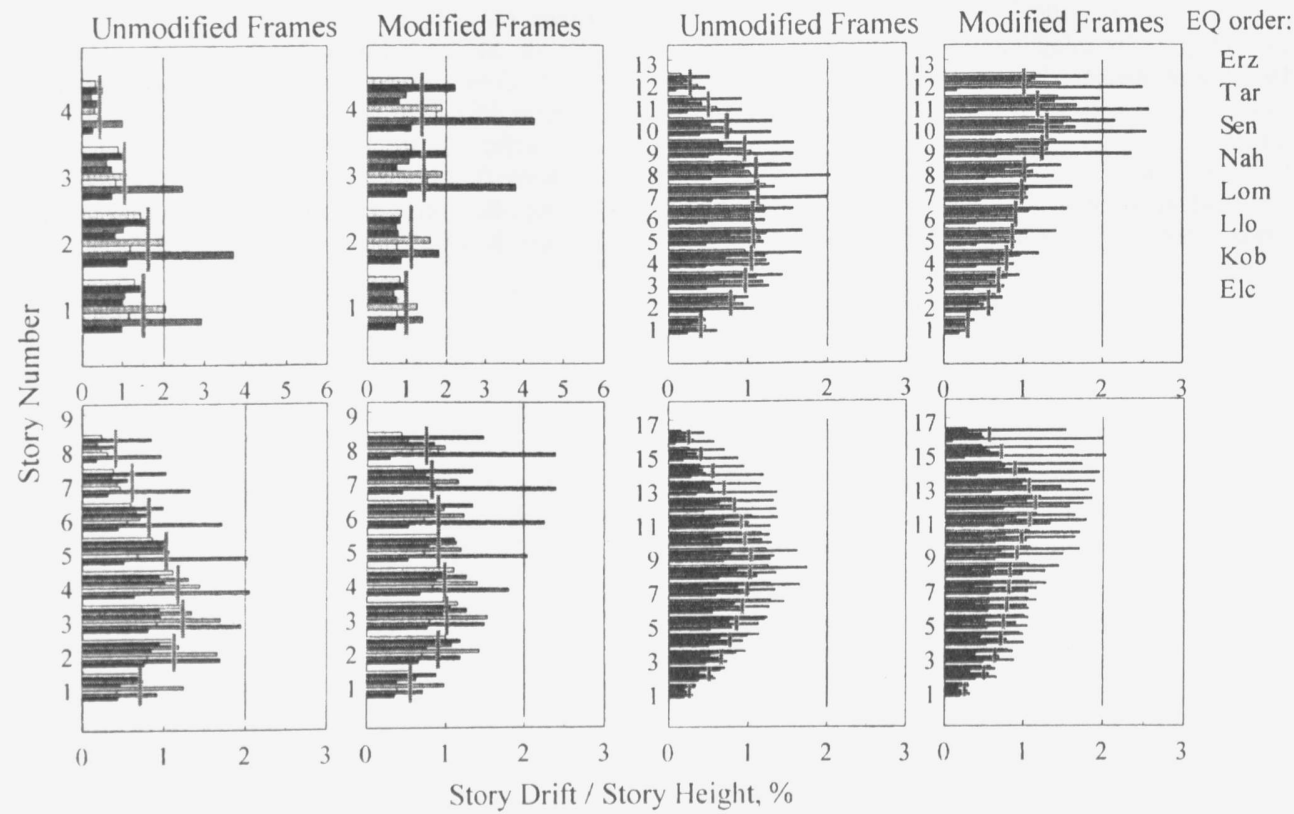

Fig. 11-Maximum story drift ratios from dynamic analysis (30 ft bays and $\mathrm{c}=0.35$ ). 
structural mechanism for the frame is found to increase with increasing number of stories. By requiring a minimum strength ratio of 1.2 , the location of column yielding for the controlling yield mechanism will be between $1 / 2$ and $2 / 3$ of the total height of the building. This implies that a large portion of the drift experienced by the building during response to strong ground motion will be concentrated in the lower portion of the building, leading to increased story drift ratios (and damage) in locations of larger axial loads.

A structural mechanism can become the controlling mechanism for regular frame structures by increasing the ratio of column to girder strengths in specific regions of the frame. If the column strengths are increased, this modification must occur over $80 \%$ of the top portion of the frame. A better option is to decrease the girder strengths by approximately $50 \%$ in the top $40 \%$ of the frame, which will usually cause the structural mechanism to become the controlling mechanism for the frame. Equation (5) may be used to estimate the required reduction factor for a given frame configuration.

The general stiffness of the frame can limit the applicability of Eq. (5) for regular concrete frames. Decreasing the girder strengths will generally lead to lower story drift ratios in the bottom half of the frame and increased story drift ratios in the upper half. The girder reduction factor cannot be applied for frames with estimated story drift ratios that exceed allowable drift limits and for frames with girder strengths that are similar to gravity load demands. For these frames, the girder and column dimensions should be slightly increased while maintaining the previous reinforcement ratios. In this way, the strength reduction factor can be applied to improve the distribution of drift over the height of the frame without violating the criteria for tolerable drift response and gravity load demands.

\section{ACKNOWLEDGMENTS}

Support provided by the National Science Foundation, NSF Grant No. 9904090 , is gratefully acknowledged.

\section{NOTATION}

$c$
$f_{c}^{\prime}$
$g$
$h_{c}$
$M_{c j}$
$M_{c t e}$
$M_{g}$
$M_{g j}$
$M_{g \cdot r e}$
$N_{b}$
$N_{s}$
$\mathrm{PGA}$
$P_{\text {max }}$
$R_{g}$

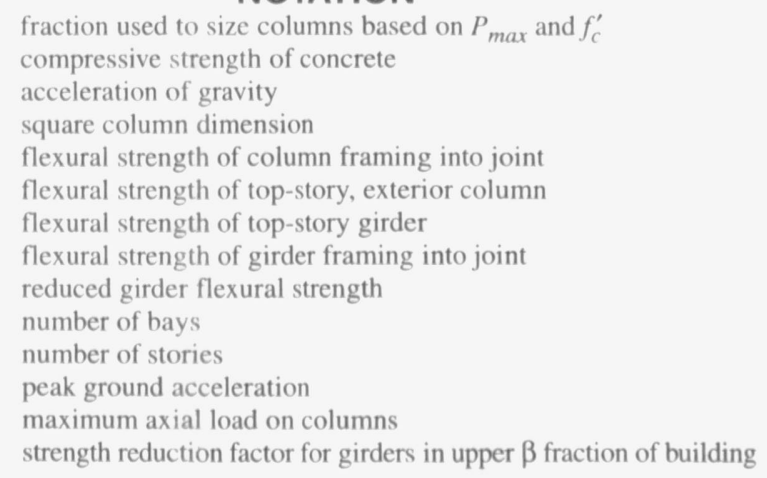

$=$ ratio of flexural strength of top story, exterior column to average girder strength

$\beta=$ fraction of total number of floor levels with reduced girder strength

\section{REFERENCES}

ACI Committee 318, 2002, "Building Code Requirements for Structural Concrete (ACI 318-02) and Commentary (318R-02)," American Concrete Institute, Farmington Hills, Mich., 443 pp

Betancourt, S., and Browning, J., 2002, "Response of Reinforced Concrete Building to Northridge Earthquake," SM Report No. 67. University of Kansas, Lawrence, Kans., May, 93 pp.

Browning, J.; Li, R.; Lynn, A; and Moehle, J. P., 2000, “Performance Assessment for a Reinforced Concrete Frame Building," EERI Spectra, V. 16. No. 3, Aug., pp. 541-555

Eberhard, M. O., and Sozen, M. A., 1989, "Experiments and Analyses to Study the Seismic Response of Reinforced Concrete Frame-Wall Structures with Yielding Columns," Structural Research Series No. 548. Civil Engineering Studies, University of Illinois, Urbana, Ill., 424 pp.

Hognestad, E., 1951, “A Study of Combined Bending and Axial Load in Reinforced Concrete Members," Bulletin Series No. 399. University of Illinois Engineering Experiment Station, Urbana, III., 128 pp.

Kuntz, G., and Browning, J., 2001, "Analysis of Method for Improving the Performance of Reinforced Concrete Frame Buildings During Earthquakes," SM Report No. 61, University of Kansas, Lawrence, Kans., June. $188 \mathrm{pp}$.

Lepage, A., 1997, "A Method for Drift-Control in Earthquake-Resistant Design of Reinforced Concrete Building Structures," PhD thesis, University of Illinois at Urbana, III.

Lopez, R. R., 1988, "Numerical Model for Nonlinear Response of R/C Frame-Wall Structures," PhD thesis, University of Illinois, Urbana, III.

Matamoros, A., and Sozen. M. A.. 2003, "Drift Limits of High-Strength Concrete Columns Subjected to Load Reversals," Journal of Structural Engineering, ASCE, V. 129, No. 3, Mar., pp. 297-313.

Moehle, J. P., and Sozen, M. A., 1978, "Earthquake-Simulation Tests of a Ten-Story Reinforced Concrete Frame with a Discontinued First-Level Beam," Structural Research Series No. 451. Civil Engineering Studies. University of Illinois, Urbana, Ill., $162 \mathrm{pp}$.

Moehle, J. P., and Sozen, M. A., 1980, "Experiments to Study Earthquake Response of R/C Structures with Stiffness Interruptions." Structural Research Series No. 482. Civil Engineering Studies. University of Illinois. Urbana, Ill., 421 pp.

Otani, S., and Sozen, M. A., 1972. "Behavior of Multistory Reinforced Concrete Frames During Earthquakes," Structural Research Series No. 392. Civil Engineering Studies, University of Illinois, Urbana, III.. 551 pp.

Park, R.; Priestley, M. J. N.; and Gill. W. D., 1982. "Ductility of SquareConfined Concrete Columns," Journal of the Structural Division. ASCE. V. 108, No. 4, pp. 929-950.

Saiidi, M., and Sozen, M. A., 1979a, "Simple and Complex Models for Nonlinear Seismic Response of Reinforced Concrete Structures." Structural Research Series No. 465, Civil Engineering Studies, University of Illinois. Urbana, Ill., 188 pp.

Saiidi, M.. and Sozen. M. A.. 1979b, "User's Manual for the LARZ Family: Computer Programs for Nonlinear Seismic Analysis of Reinforced Concrete Planar Structures," Structural Research Series No. 466. Civil Engineering Studies, University of Illinois, Urbana, Ill., 56 pp.

Takeda, T. M.; Sozen, M. A.: and Nielsen, N. N.. 1970, "Reinforced Concrete Response to Simulated Earthquakes," Journal of the Structural Division, ASCE, V. 96, No. 12, pp. 2557-2573. 